Voix et Images

voixetimages

\title{
Table des matières du volume XIII
}

Volume 14, numéro 1 (39), automne 1988

France Théoret : narratrice de la subjectivité

URI : https://id.erudit.org/iderudit/200764ar

DOI : https://doi.org/10.7202/200764ar

Aller au sommaire du numéro

Éditeur(s)

Université du Québec à Montréal

ISSN

0318-9201 (imprimé)

1705-933X (numérique)

Découvrir la revue

Citer ce document

(1988). Table des matières du volume XIII. Voix et Images, 14(1), 154-155.

https://doi.org/10.7202/200764ar

Ce document est protégé par la loi sur le droit d'auteur. L'utilisation des services d'Érudit (y compris la reproduction) est assujettie à sa politique d'utilisation que vous pouvez consulter en ligne.

https://apropos.erudit.org/fr/usagers/politique-dutilisation/
Cet article est diffusé et préservé par Érudit.

Érudit est un consortium interuniversitaire sans but lucratif composé de l’Université de Montréal, l'Université Laval et l'Université du Québec à Montréal. Il a pour mission la promotion et la valorisation de la recherche. https://www.erudit.org/fr/ 


\section{TABLE DES MATIÈRES DU VOLUME XIII}

ANSTEE, Rod, Hélène BÉDARD, Maurice POTEET, «Bibliographie de Jack Kerouac», 3, p. 426-435.

BALLON AGUIRRE, Enrique, «l'Indien imaginaire», 2, p. 330-333; «Des manifestes et des graffiti», 3, p. 489-491.

ANCTIL, Pierre, «Jack Kerouac anachronique», 3, p. 408-412.

ANDRES, Bernard, «Avant-propos», 1, p. 5-6; «Avant-propos», 2, p. 212; «Avant-propos», 3, p. 372-373; «Une si belle entrée, un si beau départ, Robert...», 2, p. 344-347.

BISHOP, Neil, «le Personnage français dans quelques romans québécois contemporains», 1, p. 82-103.

BRAULT, Jacques, «la Voix minimale», 1, p. 66-69.

BROCHU, André, «l'Interrogation totale de la mort», 1, p. 165-174; «les Grands Ténors», 2, p. 348-356; «Des Rats et des livies», 3, p. 506-514.

CHAMBERLAND, Roger et André GERVAIS, «Bibliographie de Roger Des Roches», 2, p. 280-290.

DE BELLEFEUILLE, Normand, «Incroyable Des Roches!», 2, p. 247-248.

DES ROCHES, Roger, «l'Homme qui ne souffrait plus (cœur complet). Inédit», 2, p. 215-216.

DION, Robert, «la France et nous après la Seconde Guerre mondiale», 2, p. 292 303.

FAVREAU, Francis, «Jack Kerouac: la feinte et l'écriture», 3, p. 413-421.

FERLAND, Rémi, «les Enjeux de la rencontre internationale Jack Kerouac», 3, p. 422-425.

FISETTE, Jean, «la Poésie de Paul-Marie Lapointe», 1, p. 174-179; «la Pensée critique en noir et blanc», 3, p. 422-425.

FORTIN, Marcel, «Cette ville qui fut l'Éden», 3, p. 503-505.

GERVAIS, André, «le Propre du corps Roger. Présentation», 2, p. 214; «Comment découper le corps certain et s'en sortir avec passion. Entretien», 2, p. 217 244.

GONTHIER, Claude, «Patrick Straram ou la constellation du Bison ravi», 3, p. 436-458.

HAECK, Philippe, «l'Apprentissage de Saint-Denys Gameau», 1, p. 115-122.

HAMELIN, Louis, «Petite Conversation de taverne: entretien (ou ce qui en tient lieu)», 3, p. 380-387.

HAYWARD, Annette, "Guy Delahaye et la modernité littéraire ou la revanche des "exotistes"», 2, p. 326-329.

HÉBERT, Louis-Philippe, «Entre Roger Des Roches et l'Ecrivain public, il y a moins de distance à parcourir qu'entre Clark Kent et Superman», 2, p. 245 246.

HÉBERT, Pierre, «Jalons pour une narratologie du journal intime: le statut du récit dans le Journal d'Henriette Dessaules, 1, p. 140-157; «A l'impossible certains sont tenus», 1, p. 192-195; «Mourir. En attendant dire "Bof"...», 2, p. 339343; «Voix et images, mais de quel pays?», 3, p. 492-495.

HESBOIS, Laure, «Schéma actanciel d'un pseudo-récit: le Torrent d'Anne Hébert», 1, p. 104-114.

LAMY, Suzanne, «Souvenir d'enfance. Radom (Pologne). Inédit», 1, p. 9-17; «Du privé au politique. La Constellation du cygne de Yolande Villemaire», 1, p. 18-28.

LA RUE, Monique, «Entre France et Québec: des lieux, des liens, une voix», 1, p. $42-45$. 
LORD, Michel, «l'Effet science-fiction tous azimuts», 1, p. 180-188.

LOUDER, Dean, «les Autres littératures d'expression française en Amérique du nord $x, 2$, p. 334-335.

MAJOR, Robert, «l'Instinct territorial», 1, p.161-164; «la Passion biographique», 3, p. 474-477.

MARCHETERRE, Jacquelin, «Problèmes de l'incomplétude du texte: Une prochaine roue», 2, p. 249-257.

MARQUIS, André, «Roger Des Roches: le pont surréaliste entre le cul et l'écriture», 2, p. 270-279.

MICHON, Jacques, «Couples», 1, p. 189-191.

MILOT, Pierre, «Tel Quel ou les conditions d'émergence des Herbes rouges», 2, p. 317-325.

NOIZET, Pascale, «Bibliographie de Suzanne Lamy», 1, p. 70-80.

O'REILLY, Magessa, «Grignon plurilingue», 1, p. 123-129.

PAGE, Norman, «Borduas peintre et ... écrivain?», 3, p. 478-482.

PERREAULT, Guy, «Jack Kerouac: une conscience de la mort», 3, p. 402-407.

PIETTE, Alain, «Avatars d'un pacte amoureux», 1, p. 46-51.

POTEET, Maurice, «Présentation», 3, p. 376-379; «Avant la route, le village», 3, p. 388-396.

QUINTAL, Claire, «Mémère Kerouac ou la revanche du berceau en francoaméricanie», 3, p. 397-401.

ROBERT, Lucie, «Théâtre didactique», 1, p. 196-198; «Amours, Délices et Orgues», 2, p. 357-359; «De nouvelles venues», 3, p. 515-519.

SAINT-MARTIN, Lori, «Suzanne Lamy, pour une morale de la critique», 1, p. 29 41.

SIGNORINI, Inês, «Quête d'un discours fondateur chez Jean-Claude Germain», 2, p. 304-316.

SIMON, Sherry, «Suzanne Lamy: le féminin au risque de la critique», 1, p. 52-65.

SIROIS, Antoine, «Anne Hébert et la Bible», 3, p. 459-472.

SMART, Patricia, «l'Émergence d'une culture au féminin», 1, p. 158-159; «Revenue des utopies: Nicole Brossard devant l'histoire contemporaine», 3, p. 496-498.

VIDAL, Jean-Pierre, «l'Intimité allusive ou le simulacre biographique», 2, p. 258 269.

WADDELL, Éric, «Textes de l'exode», 2, p. 336-338.

WALSH, Allan, «le Roman historique: une littérature 'nourrissante'», 3, p. 499502.

YANACOPOULO, Andrée, «Suzanne Lamy. D'un texte l'autre. Présentation», 1, p. 8. 